\title{
HPLC Chiral Stationary Phases Produced with Isolated Human Serum Albumin Fragments
}

\author{
Hisami Matsunaga, Qiang Fu, and Jun HaginaKa ${ }^{\dagger}$ \\ Faculty of Pharmaceutical Sciences, Mukogawa Women's University, \\ 11-68, Koshien Kyuban-cho, Nishinomiya, Hyogo 663-8179, Japan
}

\begin{abstract}
The enantioselectivity of HPLC chiral stationary phases produced with human serum albumin (HSA) fragments was investigated. An HSA fragment (HSA-FG75) was isolated by size-exclusion chromatography following peptic digestion of HSA. The isolated HSA-FG75 was mainly an $\mathrm{N}$-terminal half peptide with an average molecular weight of about 35000 daltons. The HSA and HSA-FG75 proteins were bound to aminopropylsilica gels activated by $N, N^{\prime}$ disuccinimidyl carbonate. Though the HSA-FG75 column showed lower enantioselectivities for all of the racemates tested than the intact HSA column, the enantioseparations of the racemates tested were attained with a shorter analysis time on the HSA-FG75 column. These results are ascribable to removal of the non-specific binding sites of HSA, changes in the globular structure of the HSA fragment and/or changes in the local environment around the binding sites. Further, the HSA-FG75 column was as stable as the intact HSA column for repetitive injection of samples.
\end{abstract}

(Received October 5, 2001; Accepted October 29, 2001)

\section{Introduction}

Proteins are composed of chiral subunits which have been shown to bind enantioselectively to chiral molecules. This property has led to the development of a number of HPLC chiral stationary phases based upon albumins such as bovine serum albumin $(\mathrm{BSA})^{1}$ and human serum albumin (HSA), ${ }^{2}$ glycoproteins such as $\alpha_{1}$-acid glycoprotein, ${ }^{3,4}$ ovomucoid, ovoglycoprotein, ${ }^{6}$ avidin $^{7}$ and cellulase ${ }^{8}$ and enzymes such as trypsin, ${ }^{9} \quad \alpha$-chymotrypsin, ${ }^{10} \quad$ lysozyme $^{11}$ and pepsin. ${ }^{12}$ Disadvantages of protein-based HPLC columns have included low capacity, lack of column ruggedness in some instances and a limited understanding of the chiral recognition mechanisms. If a chiral binding site(s) exists on a domain or fragment and if it acts independently of others, chiral columns with the desired domain or fragment should be able to be made; these could be of higher capacity and more stable. Previously, it was found that the third domain of turkey ovomucoid is enantioselective to at least two classes of compounds, benzodiazepines and 2arylpropionic acid derivatives, and that the glycosylated group is not needed for chiral recognition of these compounds. ${ }^{13}$ Further, a chiral binding site was located and the chiral recognition mechanism was elucidated by using NMR spectroscopy and computational chemistry. ${ }^{13}$

Andersson et al. ${ }^{14}$ isolated a BSA fragment of molecular weight with $\mathrm{ca} .38000$ by peptic digestion, and they cross-linked the fragment into aminopropylsilica gels by glutaraldehyde or adsorbed it on bare silica gels. We modified such methods for the isolation and binding of a BSA fragment, BSA-FG75. The intact BSA column gave higher enantioselectivity for the

† To whom correspondence should be addressed.

E-mail: haginaka@mwu.mukogawa-u.ac.jp

Q. F. present address: School of Pharmacy, Xi'an Jiaotong University, 710061, Xi' an, Shaanxi, China. majority of compounds tested than did the BSA-FG75 column, while the BSA-FG75 column gave higher enantioselectivity for lorazepam and benzoin. ${ }^{15}$ These results are due to a higher density of chiral binding sites on the BSA-FG75 column. Also, we isolated two fragments from the BSA-FG75 by anionexchange chromatography, and characterized the two fragments. The recognition properties of the two fragments were compared with those of BSA and BSA-FG75. ${ }^{16}$

In this study, an HSA fragment(s) was prepared by peptic digestion of half-cystinyl HSA. The crude HSA fragment was isolated by size exclusion chromatography, and the obtained HSA fragment, HSA-FG75, was bound to $N, N^{\prime}$-disuccinimidyl carbonate (DSC)-activated aminopropylsilica gels. The retentive and enantioselective properties of the HSA-FG75 column were compared with those of the intact HSA column. Further, we discussed chiral recognition sites on the HSA fragment and the utility of the HSA fragment column.

\section{Experimental}

\section{Reagents and materials}

HSA and pepsin were purchased from Sigma-Aldrich Japan (Tokyo, Japan). Racemic benzoin and DSC were purchased from Nacalai Tesque (Kyoto, Japan). The racemic drugs used were kindly donated by pharmaceutical companies. The structures of these racemates are shown in Fig. 1. Silica gel (Ultron-120, particle diameter $5 \mu \mathrm{m}$, pore size $120 \AA$, surface area $300 \mathrm{~m}^{2} \mathrm{~g}^{-1}$ ) was obtained from Shinwa Chemical Industries (Kyoto, Japan). Sephadex G-75 (fine) and Sephadex G-25 (fine) were purchased from Amersham Pharmacia Biotech (Tokyo, Japan). Other solvents and reagents were used without further purification.

Water purified with a Nanopure II unit (Barnstead, Boston, MA, USA) was used for the preparation of the eluent and the sample solution. 
<smiles>O=C1Nc2ccc(Cl)cc2C(c2ccccc2)=NC1O</smiles><smiles>CC(C)Cc1ccc(C(C)C(=O)O)cc1</smiles><smiles>CC(C)C(=O)O</smiles>
Pranoprofen

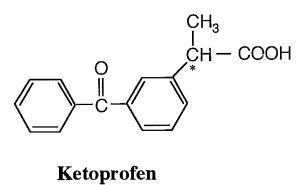

Others

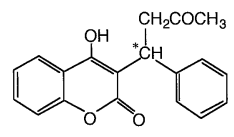

Warfarin

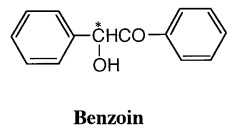

Fig. 1 Structures of the racemic solutes used in this study.

\section{Isolation of HSA fragment}

Half-cystinyl HSA was prepared according to the method of King. ${ }^{17}$ A $22.4 \mathrm{mg}$ amount of L-cystine was dissolved in $0.5 \mathrm{ml}$ of $1 \mathrm{M} \mathrm{NaOH}$ solution and this mixture was added to $47 \mathrm{ml}$ of $0.1 \mathrm{M}$ Tris buffer ( $\mathrm{pH}$ 8.0). A $1.0 \mathrm{~g}$ amount of HSA was dissolved in $34 \mathrm{ml}$ of $0.1 \mathrm{M}$ Tris buffer $(\mathrm{pH} \mathrm{8.0)}$. The two solutions were mixed and reacted at $25^{\circ} \mathrm{C}$ for $17 \mathrm{~h}$. Then, the reacted solution was dialyzed against distilled water and lyophilized. Peptic digestion of half-cystinyl HSA was performed according to the method of King and Spencer. ${ }^{18} \mathrm{~A}$ $0.124 \mathrm{~g}$ amount of half-cystinyl HSA was dissolved in $8 \mathrm{ml}$ of $0.1 \mathrm{M}$ ammonium formate buffer $(\mathrm{pH} 3.7)$ containing $3.2 \mathrm{mM}$ octanoic acid and preheated at $37^{\circ} \mathrm{C}$. A $0.25 \mathrm{mg}$ amount of pepsin was dissolved in the same buffer. The two solutions were mixed and reacted at $37^{\circ} \mathrm{C}$ for $30 \mathrm{~min}$. The reaction was stopped by the addition of $2 \mathrm{M}$ Tris buffer ( $\mathrm{pH} 8.0$ ). After dialyzing against $0.01 \mathrm{M}$ Tris buffer $(\mathrm{pH} 8.0)$ containing $0.3 \mathrm{M}$ $\mathrm{NaCl}$, the solution was applied to a Sephadex G-75 column (90 $\times 5 \mathrm{~cm}$ i.d.) that was equilibrated with $0.01 \mathrm{M}$ Tris buffer $(\mathrm{pH}$ 8.0) containing $0.3 \mathrm{M} \mathrm{NaCl}$ at an average flow rate of $80 \mathrm{ml} \mathrm{h}^{-1}$. The eluate was monitored at $280 \mathrm{~nm}$. The separation was performed at $4^{\circ} \mathrm{C}$. The second peak was collected and lyophilized. The lyophilized sample was desalted with a Sephadex G-25 (fine) column $(20 \mathrm{~cm} \times 5 \mathrm{~cm}$ i.d.) using $15 \mathrm{mM}$ $\mathrm{NH}_{4} \mathrm{HCO}_{3}$ as the buffer at an average flow rate of $120 \mathrm{ml} \mathrm{h}^{-1}$. The eluate was collected and lyophilized. The HSA fragment obtained was termed HSA-FG75.

\section{Preparation of DSC-activated aminopropylsilica gels}

A $10 \mathrm{~g}$ amount of the 3-aminopropylsilica gels was dried in vacuo over $\mathrm{P}_{2} \mathrm{O}_{5}$ at $80^{\circ} \mathrm{C}$ for $1 \mathrm{~h}$ and added to $100 \mathrm{ml}$ of dry acetonitrile. The mixture was reacted with $10 \mathrm{~g}$ of DSC for $23 \mathrm{~h}$ at $30^{\circ} \mathrm{C}$. The reaction mixture was filtered and washed with acetonitrile, water, methanol and dichlorethane. The activated silica gels were dried in vacuo over $\mathrm{P}_{2} \mathrm{O}_{5}$ at $80^{\circ} \mathrm{C}$ for $3 \mathrm{~h}$.

\section{Preparation of HSA or HSA fragment column}

HSA proteins were bound to the DSC-activated aminopropylsilica gels as follows: $0.25 \mathrm{~g}$ of the DSC-activated silica gels was slurried in $5 \mathrm{ml}$ of $20 \mathrm{mM}$ sodium phosphate buffer ( $\mathrm{pH}$ 7.8). To the mixture, $0.020 \mathrm{~g}$ of HSA proteins dissolved in $1 \mathrm{ml}$ of $20 \mathrm{mM}$ sodium phosphate buffer ( $\mathrm{pH}$ 6.60) was added slowly at room temperature for $1 \mathrm{~h}$ and the mixture was further stirred for $20 \mathrm{~h}$ at $30^{\circ} \mathrm{C}$ at $\mathrm{pH} 6.60$. Similarly, the HSA fragments were bound to DSC-activated silica gels as follows: $0.25 \mathrm{~g}$ of the DSC-activated silica gels was reacted with $0.010 \mathrm{~g}$ of the HSA-FG75 using the same reaction conditions. Then both the reaction mixtures were filtered and washed with water and slurry solvent as described below. The HSA and HSA-FG75 materials were packed into a stainlesssteel column $(2 \mathrm{~mm}$ i.d. $\times 100 \mathrm{~mm})$ by the slurry packing method. The slurry solvents were 5\% ethanol for the HSA materials and $50 \mathrm{mM}$ sodium phosphate buffer $(\mathrm{pH}$ 7.5)-1propanol $(60: 40, \mathrm{v} / \mathrm{v})$ for the HSA-FG75 materials. The same packing solvents were used.

\section{Chromatography}

For chiral resolution of racemic solutes on the HSA and HSAFG75 columns, the HPLC system used was composed of an LC10AD pump, an SPD-10A spectrophotometer, a Rheodyne Model 7125 injector, a C-R6A integrator and an SCL-10A system controller (all from Shimadzu, Kyoto, Japan). The flow-

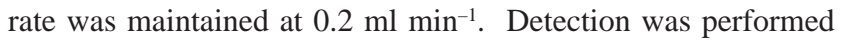
at $210 \mathrm{~nm}$. Retention factors $(k)$, enantioseparation factors $(\alpha)$, and resolutions $(R s)$ of the racemates were calculated. All separations were carried out at $25^{\circ} \mathrm{C}$ using a water bath.

\section{$N$-Terminal sequencing}

A $110 \mathrm{mg}$ amount of the HSA fragment was reconstituted with $160 \mu \mathrm{l}$ of water. A $5 \mu \mathrm{l}$ portion of the solution was spotted onto a solid support for $N$-terminal sequencing analysis using an ABI 473A protein sequencer (Perkin-Elmer Biosystems, Tokyo, Japan).

\section{Matrix-assisted laser-desorption ionization time-of-flight} (MALDI-TOF) mass spectrometry

MALDI-TOF mass spectra were measured using a Vision 2000 reflector-type TOF instrument (Thermoquest, Tokyo, Japan) equipped with an $\mathrm{N}_{2}$ laser operating at a wavelength of $337 \mathrm{~nm}$ with a pulse duration of $6 \mathrm{~ns}$. The ions generated were accelerated to a potential of $5 \mathrm{kV}$ in the ion source and postaccelerated to a potential of $20 \mathrm{kV}$ for detection with a secondary ion multiplier. The MALDI-TOF mass spectra represent the accumulation of 15 - 20 single laser shots. They were calibrated externally by a standard sample (bovine serum albumin, molecular weight of 66430) that was placed on the same target. The matrix used was 2,5-dihydroxybenzoic acid, dissolved in a 2:1 (v/v) mixture of $0.1 \mathrm{v} / \mathrm{v} \%$ aqueous trifluoroacetic acid (TFA) and acetonitrile at a concentration of $50 \mathrm{mM}$. Samples were dissolved in water at a concentration of $10^{-6} \mathrm{M}$. A $0.5 \mu \mathrm{l}$ portion of the sample solution was mixed with an equal volume of the matrix solution on the target, resulting in a sample of $500 \mathrm{fmol}$. After deposition on the stainless-steel target, the sample was air-dried and then introduced into the mass spectrometer.

\section{Results and Discussion}

Characterization of HSA fragment

Figure 2 shows a chromatogram of half-cystinyl HSA 


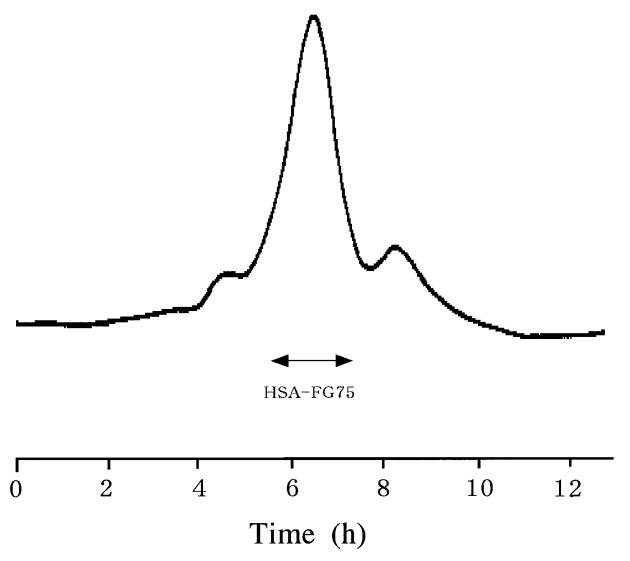

Fig. 2 Chromatogram of peptic digest of HSA on a size exclusion column. Column, Sephadex G-75 $(5 \mathrm{~cm}$ i.d. $\times 90 \mathrm{~cm})$; eluent, $0.01 \mathrm{M}$ Tris buffer ( $\mathrm{pH} 8.0$ ) containing $0.3 \mathrm{M} \mathrm{NaCl}$; flow rate, $80 \mathrm{ml} \mathrm{h}^{-1}$, detection wavelength, $280 \mathrm{~nm}$.
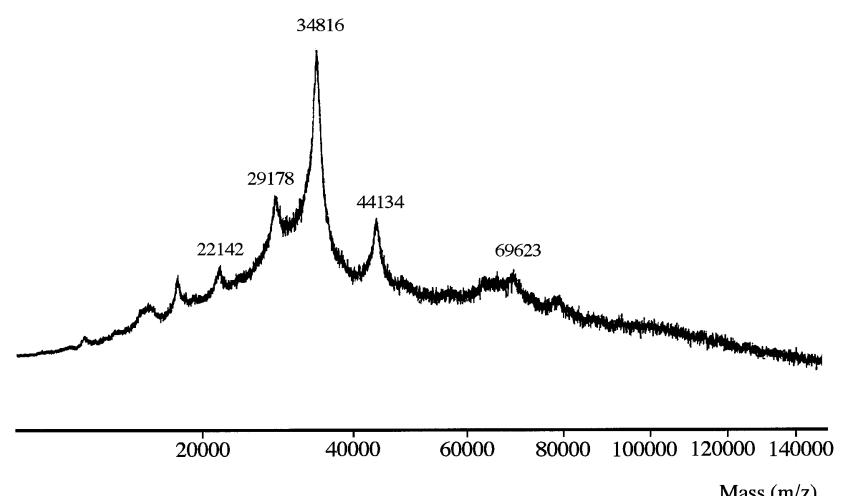

Fig. 3 MALDI-TOF mass spectrum of HSA-FG75. Flight mode, reflector-type; matrix, 2,5-dihydroxybenzoic acid. Other conditions as in Experimental.

digested by pepsin on a Sephadex G-75 size-exclusion column. The fraction of the HSA fragment, HSA-FG75, was collected. The purity of the HSA-FG75 protein was checked using a linear gradient of a mixture of water and acetonitrile including TFA on a C18 column. It was found that the isolated HSA-FG75 fraction was free from uncleaved HSA, and that the HSA-FG75 was a mixture of peptides. Figure 3 shows the MALDI-TOF mass spectra of the HSA-FG75. MALDI-TOF mass spectra indicated three $(\mathrm{M}+\mathrm{H})^{+}$ion peaks, whose molecular weights are estimated to be 34816, 29178 and 44134 daltons. The molecular weights estimated are in good agreement with the predicted molecular weights of amino acid sequences $1-308$, 49-308 and 1-387. The fragment protein whose molecular weight is about 35000 daltons was mainly observed. The results obtained are good agreement with those reported by Heaney-Kieras and King. ${ }^{19}$ Further, the $N$-terminal amino acid of the HSA-FG75 started from Asp, which is the $N$-terminus of the uncleaved HSA. Also, the $N$-terminal sequencing results for HSA-FG75 showed that its amino acid sequence was Asp-AlaHis-Lys-Ser-Glu-Val-Ala-His-Arg-Phe-Lys-Asp-Leu-Gly. This sequence corresponds to the known amino acid sequence of HSA. ${ }^{20}$ These results reveal that the isolated HSA-FG75 is mainly an $\mathrm{N}$-terminal half peptide with an average molecular weight of about 35000 .
Table 1 Amounts of HSA and HSA-FG75 bound to DSCactivated silica gels

\begin{tabular}{lccc}
\hline Material & $\begin{array}{c}\text { Reacted protein, } \\
\mu \mathrm{mol} / \mathrm{g} \text { silica }\end{array}$ & $\begin{array}{c}\text { Bound protein, } \\
\mu \mathrm{mol} / \mathrm{g} \text { silica }\end{array}$ & Bound ratio, \% \\
\hline HSA & 1.20 & $1.17 \pm 0.03$ & $96.9 \pm 0.57$ \\
HSA-FG75 & 1.19 & $1.19 \pm 0.00$ & $100 \pm 0.01$ \\
\hline
\end{tabular}

$n=3$.

Table 2 Retention factor, enantioseparation factor and resolution of benzodiazepine, 2-arylpropionic acid derivatives, warfarin and benzoin on HSA and HSA fragment columns ${ }^{\mathrm{a}}$

\begin{tabular}{|c|c|c|c|c|c|c|}
\hline \multirow{3}{*}{ Compound } & \multicolumn{6}{|c|}{ Column } \\
\hline & \multicolumn{3}{|c|}{ HSA } & \multicolumn{3}{|c|}{ HSA-FG75 } \\
\hline & $k_{1}^{\mathrm{b}}$ & $\alpha$ & $R s$ & $k_{1}$ & $\alpha$ & $R s$ \\
\hline \multicolumn{7}{|l|}{ Benzodiazepine } \\
\hline Oxazepam ${ }^{\mathrm{c}}$ & 1.98 & 8.32 & 8.64 & 1.73 & 1.86 & 2.12 \\
\hline \multicolumn{7}{|c|}{ 2-Arylpropionic acid } \\
\hline Ibuprofen $^{\mathrm{d}}$ & 2.37 & 1.89 & 2.45 & 0.81 & 1.60 & 0.77 \\
\hline Ketoprofen ${ }^{\mathrm{e}}$ & 39.5 & 1.26 & 1.24 & 4.82 & 1.24 & 0.73 \\
\hline Pranoprofen ${ }^{\mathrm{e}}$ & 29.9 & 1.95 & 3.60 & 6.43 & 1.45 & 1.47 \\
\hline Flurbiprofen ${ }^{\mathrm{d}}$ & 6.07 & 1.43 & 1.37 & 1.86 & 1.28 & 0.55 \\
\hline \multicolumn{7}{|l|}{ Others } \\
\hline Warfarin ${ }^{\mathrm{e}}$ & 13.5 & 2.19 & 3.08 & 2.75 & 1.55 & 1.34 \\
\hline Benzoin $^{f}$ & 1.87 & 1.17 & 0.58 & 1.36 & 1.00 & - \\
\hline
\end{tabular}

a. HPLC conditions: column size, $2.0 \mathrm{~mm}$ i.d. $\times 100 \mathrm{~mm}$; flow rate, $0.2 \mathrm{ml} \mathrm{min}{ }^{-1}$; detection, $210 \mathrm{~nm}$; temperature, $25^{\circ} \mathrm{C}$; loaded amount, $100 \mathrm{ng}$. The data given are averages of the values obtained with three different batch columns.

b. The retention factor of the first eluted enantiomer

c. The eluent used is $50 \mathrm{mM}$ sodium phosphate buffer( $\mathrm{pH}$ 7.5)-1propanol $(96: 4, \mathrm{v} / \mathrm{v})$.

d. The eluent used is $50 \mathrm{mM}$ sodium phosphate buffer( $\mathrm{pH}$ 6.9)-1propanol $(85: 15, \mathrm{v} / \mathrm{v})$ containing $4 \mathrm{mM}$ octanoic acid.

e. The eluent used is $50 \mathrm{mM}$ sodium phosphate buffer( $\mathrm{pH}$ 7.5)-1propanol $(94: 6, \mathrm{v} / \mathrm{v})$.

f. The eluent used is $50 \mathrm{mM}$ sodium phosphate buffer( $\mathrm{pH} 7.5)-1$ propanol $(98: 2, \mathrm{v} / \mathrm{v})$.

Comparison of retention factor, enantioseparation factor and resolution of racemic solutes on HSA and HSA-FG75 columns

The bound amounts of HSA and HSA-FG75 per $1 \mathrm{~g}$ of the DSC-activated silica gel are shown in Table 1. The bound amounts of HSA and HSA-FG75, respectively, were 1.17 and $1.19 \mu \mathrm{mol}$ per $1 \mathrm{~g}$ of the activated silica gel. They were reproducibly bound to the DSC-activated silica gels.

Table 2 shows the retention factors, enantioseparation factors and resolution of various racemates on HSA and HSA-FG75 columns. Though the retentivity and enantioselectivity of all solutes tested were lower on the HSA-FG75 column than on the HSA column, benzodiazepine (oxazepam), 2-arylpropionic acid derivatives (ibuprofen, ketoprofen, pranoprofen and flurbiprofen) and warfarin were still enantioseparated on the HSA-FG75 column. However, no enantioseparation of benzoin was attained. As reported by He and Carter, ${ }^{21}$ primary binding sites for benzodiazepines and 2-arylpropionic acid derivatives are located in the subdomain IIIA, while that of warfarin in the subdomain IIA. It is interesting that benzodiazepine (oxazepam) and 2-arylpropionic acid derivatives (ibuprofen, ketoprofen, pranoprofen and flurbiprofen) participate in 
(A) HSA

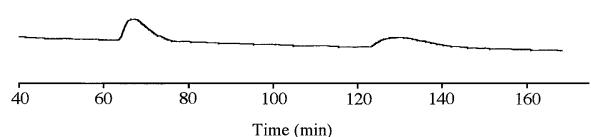

(B)

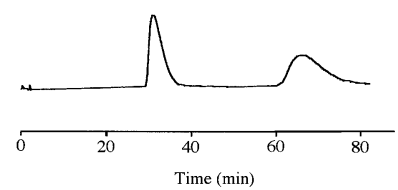

Fig. 4 Chromatograms of pranoprofen (A) and warfarin (B) on HSA and HSA-FG75 columns. HPLC conditions as in Table 2.

enantioselective binding interaction with the $N$-terminal half of HSA, despite the fact that the primary binding sites of these compounds are on the other half of HSA. Figure 4 shows the enantioseparations of pranoprofen and warfarin on the HSA and HSA-FG75 columns. Though the HSA column showed higher enantioselectivity than the HSA-FG75 column, the enantioseparations of pranoprofen and warfarin were attained with a shorter analysis time on the HSA-FG75 column. This could be due to removal of the non-specific binding sites of HSA, changes in the globular structure of the HSA fragment and/or changes in the local environment around the binding sites. Further, the HSA-FG75 column was as stable as the intact HSA column for repetitive injection of samples. These results suggest that the HSA fragment column could be useful for the enantioseparation of solutes having strong affinities for HSA.

\section{Conclusion}

An HSA fragment (HSA-FG75) isolated by size-exclusion chromatography following peptic digestion of HSA was an $N$ terminal half peptide with an average molecular weight of about 35000 daltons. Though the HSA-FG75 column showed lower enantioselectivities for all of the racemates tested than the intact HSA column, the enantioseparations of the racemates tested were attained with a shorter analysis time on the HSA-FG75 column. These results are ascribable to removal of the non- specific binding sites of HSA, changes in the globular structure of the HSA fragment and/or changes in the local environment around the binding sites. Further, the HSA-FG75 column was as stable as the intact HSA column for repetitive injection of samples.

\section{References}

1. S. Allenmark, J. Liq. Chromatogr., 1986, 9, 425.

2. E. Domenici, C. Bertucci, P. Salvadori, G. Felix, I. Cahagne, S. Montellier, and I. W. Wainer, Chromatographia, 1990, 29, 170.

3. J. Hermansson, J. Chromatogr., 1983, 269, 71.

4. J. Haginaka and H. Matsunaga, Enantiomer, 2000, 5, 37.

5. T. Miwa, M. Ichikawa, M. Tsuno, T. Hattori, T. Miyakawa, M. Kayano, and Y. Miyake, Chem. Pharm. Bull., 1987, 35, 682.

6. J. Haginaka, C. Seyama, and N. Kanasugi, Anal. Chem., 1995, 67, 2539.

7. T. Miwa, T. Miyakawa, and Y. Miyake, J. Chromatogr., 1988, 457, 227.

8. P. Erlandsson, I. Marle, L. Hansson, R. Isaksson, C. Petterson, and G. Petterson, J. Am. Chem. Soc., 1990, 112, 4573.

9. S. Thelohan, P. Jadaud, and I. W. Wainer, Chromatographia, 1989, 28, 551.

10. I. W. Wainer, P. Jadaud, G. R. Schombaum, S. V. Kadodlar, and M. P. Henry, Chromatographia, 1988, 25, 903.

11. J. Haginaka, T. Murashima, and C. Seyama, J. Chromatogr. A, 1994, 666, 203.

12. J. Haginaka, Y. Miyano, Y. Saizen, C. Seyama, and T. Murashima, J. Chromatogr. A, 1995, 708, 161.

13. T. C. Pinkerton, W. J. Howe, E. L. Urlich, J. P. Comiskey, J. Haginaka, T. Murashima, W. F. Walkenhorst, W. M. Westler, and J. L. Markley, Anal. Chem., 1995, 67, 2354.

14. S. Andersson, S. Allenmark, P. Erlandsson, and S. Nilsson, J. Chromatogr., 1990, 498, 81.

15. J. Haginaka and N. Kanasugi, J. Chromatogr. A, 1995, 694, 71.

16. J. Haginaka and N. Kanasugi, J. Chromatogr. A, 1997, 769, 215.

17. T. P. King, Arch. Biochem. Biophys., 1973, 156, 509.

18. T. P. King and M. Spencer, J. Biol. Chem., 1970, 245, 6134.

19. J. Heaney-Kieras and T. P. King, J. Biol. Chem., 1977, 252, 4326.

20. B. Meloun, L. Moravek, and V. Kostka, FEBS Lett., 1975, $58,134$.

21. X. M. He and D. C. Carter, Nature, 1992, 358, 209. 